\title{
A new view to uncertainty in Electre III method by introducing interval numbers
}

\author{
Mohammad Kazem Sayyadi and Ahmad Makui*
}

Department of Industrial Engineering, Iran University of Science and Technology, Tehran, Iran

\begin{tabular}{l}
\hline A R T I C L E I N F O \\
\hline Article history: \\
Received March 29, 2012 \\
Accepted 18 June 2012 \\
Available online \\
June 19 2012 \\
\hline Keywords: \\
Electre III \\
Concordance \\
Interval numbers \\
Uncertainty
\end{tabular}
A B S T R A C T

\begin{abstract}
The Electre III is a widely accepted multi attribute decision making model, which takes into account the uncertainty and vagueness. Uncertainty concept in Electre III is introduced by indifference, preference and veto thresholds, but sometimes determining their accurate values can be very hard. In this paper we represent the values of performance matrix as interval numbers and we define the links between interval numbers and concordance matrix .Without changing the concept of concordance, in our propose concept, Electre III is usable in decision making problems with interval numbers.
\end{abstract}

(c) 2012 Growing Science Ltd. All rights reserved.

\section{Introduction}

Multiple criteria decision making (MCDM) is the process of determining the best feasible solution in the presence of multiple, generally conflicting criteria (Sayadi et al., 2009; Catalina et al., 2011). The non-compensatory approaches in MCDM are based on the comparisons between the alternatives, which are made with respect to non-compensatory criteria. The family of ELECTRE constitutes an important part of non-compensatory methods. ELECTRE III (Roy, 1968) considers imprecision and uncertainty in data and uses pseudo criteria for constructing outranking relations between alternatives. ELECTRE III is the most popular method in the ELECTRE family and it has been remarkably implemented. For example, in the optimization of decentralized energy systems (Roy, 1978), sustainable energy planning (Roy, 1996), network improvement and choosing route for Dublin port motorway (Roy,1991), ranking of British universities (Giannoulis \& Ishizaka, 2010) and selection of production processes of thin-film solar technology (Cavallaro, 2010) and ranking alternatives in the renewable energy sector. Based on the above formulation and notation we can use the concept of concordance in Electre III for comparing and ranking interval numbers.

\footnotetext{
* Corresponding author. Tel: +9892177240000

E-mail addresses: amakui@iust.ac.ir (A. Makui) 
The performance values in the decision matrix are assumed to be certain and accurate. However, the notion of uncertainty is mentioned by two parameters named indifference threshold and preference threshold used to compute the credibility of outranking relations. In this paper, we propose a new view, which transfers the concept of uncertainty from the indifference and preference thresholds to performance values in the decision matrix. For this purpose, the performances of the criteria for alternatives are assumed to be interval numbers. In many types of real world decision making problems, it can be an unrealistic assumption that the knowledge and evaluation of a decision maker about the performance values are so accurate and precise. Often a decision-maker can evaluate the performance of various alternatives in relation to considered attributes, by interval numbers. In such situation, the comparison of two actions leads to the comparison of two interval numbers. In this paper, we introduce new relations based interval numbers in decision matrix, to compute the concordance and discordance values in ELECTRE III method.

\section{Electre III}

This section presents some elementary concepts, definitions, and the notation used in the ELECTRE III method. We consider a decision making problem involving the ranking of $n$ alternatives $A=$ $\left\{a_{1}, a_{2}, \ldots, a_{n}\right\}$, which are evaluated in terms of $m$ attributes $\left(g_{1}, g_{2}, \ldots, g_{m}\right)$. The weighted coefficients of attributes are $\left(w_{1}, w_{2}, \ldots, w_{m}\right)$ respectively. The attribute are real-valued functions defined on the set A so that $g_{j}\left(a_{i}\right)$ represents the performance of the $i$-th alternative with respect to the $j^{\text {th }}$ attribute. A pseudo-criterion is a preference model including two different thresholds: a preference threshold $p_{i}\left(g_{i}(a)\right)$ for criterion $g_{i}$ for all $a \in A$ and an indifference threshold $q_{i}\left(g_{i}(a)\right)$ for criterion $g_{i}$ for all $a \in A$ such that $p_{i}\left(g_{i}(a)\right) \geq q_{i}\left(g_{i}(a)\right)$ for all $g_{i}(a)$ and $a \in A$ and also $g_{i}(a)+p_{i}\left(g_{i}(a)\right)$ and $g_{i}(a)+q_{i}\left(g_{i}(a)\right)$ are non-decreasing monotone functions of $g_{i}(a)[11,12]$. The alternative $a$ is considered better than alternative $b$ according to the criterion $i$ when $g_{i}(a)>g_{i}(b)$. The aim of the thresholds of preference, indifference and veto are identifying the statement $a S b$ for every couple $a, b$ of the set A. The statement $a S b$ means that alternative $a$ outranks alternative $b$, when $a$ outranks (is at least as good as) $b$ in most of the criteria and never significantly worse in the rest of them. The statement $a S_{i} b$ is defined for criterion $i$, similarly. The criterion $i$ is in agreement with $a S b$ if only $a S_{i} b$ or $g_{i}(a)>g_{i}(b)-q_{i}\left(g_{i}(a)\right)$. Electre III uses concordance and discordance matrices for determining acceptability of assertion $a S b$. The concordance relations represent the level of majority among the criteria in favor of the assertion $a S b$. Each criterion $g_{i}$ has a weight $w_{i}>0$ representing its importance so that $\sum_{i} w_{i}=1$. Therefore, if it is assumed that the objective functions of all criteria should be maximized the concordance relation $\mathrm{C}(\mathrm{a}, \mathrm{b})$ can be written as follows:

$$
\begin{aligned}
& C(a, b)=\sum_{i} w_{i} C_{i}(a, b) \text { in accordance with } \\
& C_{i}(a, b)=1 \quad \text { if } g_{i}(a) \geq g_{i}(b)-q_{i}\left(g_{i}(a)\right) \\
& C_{i}(a, b)=0 \quad \text { if } g_{i}(a) \leq g_{i}(b)-p_{i}\left(g_{i}(a)\right) \\
& C_{i}(a, b)=\frac{p_{i}\left(g_{i}(a)\right)+g_{i}(a)-g_{i}(b)}{p_{i}\left(g_{i}(a)\right)-q_{i}\left(g_{i}(a)\right)} \quad \text { Otherwise }
\end{aligned}
$$

The discordance matrix can be calculated as long as the veto threshold $v_{i}$ has been defined. Veto threshold $v_{i}$ allows the complete rejection of the $a S b$ statement when the relation $g_{i}(b) \geq g_{i}(a)-$ $v_{i}\left(g_{i}(a)\right)$ is valid for each criterion $i$. For each criterion $g_{i}$ discordance relation $d_{i}$ is determined by the following formulation:

$d_{i}(a, b)=1$

if $g_{i}(a) \leq g_{i}(b)-v_{i}\left(g_{i}(a)\right)$ 
$d_{i}(a, b)=0$

$d_{i}(a, b)=\frac{g_{i}(b)-g_{i}(a)-p_{i}\left(g_{i}(a)\right)}{v_{i}\left(g_{i}(a)\right)-p_{i}\left(g_{i}(a)\right)}$
If $g_{i}(a)>g_{i}(b)-p_{i}\left(g_{i}(a)\right)$

Using the concordance and discordance matrices, an outranking credibility degree is defined as follows:

$$
\begin{array}{lrl}
S(a, b) & =C(a, b) & \text { if } d_{i}(a, b) \leq C(a, b) \text { for each criterion i } \\
S(a, b) & =C(a, b) \prod_{i \in K} \frac{\left(1-d_{i}(a, b)\right)}{1-C(a, b)} & \text { Otherwise }
\end{array}
$$

where $K$ is the group of the criteria for which the statement $d_{i}(a, b)>C(a, b)$ is valid and credibility degree $S(a, b)$ indicate the degree to which $a$ outranks $b$.

It is possible to define a family of nested crisp outranking relations $S^{\alpha}=\{(a, b) \in A \times A: S(a, b) \geq$ $\alpha\}, 0.5 \leq \alpha \leq 1$ based on the valued outranking relation $S(a, b)$. These crisp outranking relations correspond to $\alpha$-cuts of $S(a, b)$, where the cutting level $\alpha$ represents the minimum value for $S(a, b)$ so that $a S^{\alpha} b$ is true (Rogers \& Bruen, 2000).

It is possible to assume that the veto thresholds $v_{i}\left(g_{i}(a)\right)$ are defined so large that there is no discordance. When no veto thresholds are specified or veto thresholds are defined so large, the discordance indices in terms of each decision criterion are all equal to zero. In this case the $S(a, b)=$ $C(a, b)$ (Papadopoulos, \& Karagiannidis, 2008).

\section{Uncertainty as interval numbers in Electre III}

In Electre III method, preference threshold $p_{i}\left(g_{i}\left(a_{j}\right)\right)$ for criterion $g_{i}$ for all $a_{j} \in A$ and indifference threshold $q_{i}\left(g_{i}\left(a_{j}\right)\right)$ for criterion $g_{i}$ for all $a_{j} \in A$ is defined by decision maker or expert. Suppose that $\alpha_{i j}=q_{i}\left(g_{i}\left(a_{j}\right)\right) / p_{i}\left(g_{i}\left(a_{j}\right)\right)$. By this definition the elements of decision matrix can be extended to interval $\left[g_{i}^{L}\left(a_{j}\right), g_{i}^{U}\left(a_{j}\right)\right]=\left[g_{i}\left(a_{j}\right), g_{i}\left(a_{j}\right)+p_{i}\left(g_{i}\left(a_{j}\right)\right)\right]$ and $\left[g_{i}^{L}\left(a_{j}\right), g_{i}^{U}\left(a_{j}\right)\right]=\left[g_{i}\left(a_{j}\right)-\right.$ $\left.p_{i}\left(g_{i}\left(a_{j}\right)\right), g_{i}\left(a_{j}\right)\right]$ if $i$-th criterion is benefit criterion and cost criterion, respectively. So $p_{i}\left(g_{i}\left(a_{j}\right)\right)=g_{i}^{U}\left(a_{j}\right)-g_{i}^{L}\left(a_{j}\right)$ and $q_{i}\left(g_{i}\left(a_{j}\right)\right)=\alpha_{i j}\left(g_{i}^{U}\left(a_{j}\right)-g_{i}^{L}\left(a_{j}\right)\right)$. Based on these relations concordance relations can be rewrite as follows ( $i$-th criterion is benefit criterion and $a_{t}$ and $a_{s}$ are two alternatives):

$C_{i}\left(a_{t}, a_{s}\right)=1$

$C_{i}\left(a_{t}, a_{s}\right)=0$

$$
\begin{aligned}
& \text { if } \alpha_{i t} g_{i}^{U}\left(a_{t}\right)+\left(1-\alpha_{i t}\right) g_{i}^{L}\left(a_{t}\right) \geq g_{i}^{L}\left(a_{s}\right) \\
& \quad \text { if } g_{i}^{U}\left(a_{t}\right) \leq g_{i}^{L}\left(a_{s}\right)
\end{aligned}
$$

$C_{i}\left(a_{t}, a_{s}\right)=\frac{g_{i}^{U}\left(a_{t}\right)-g_{i}^{L}\left(a_{s}\right)}{\left(1-\alpha_{i t}\right)\left(g_{i}^{U}\left(a_{t}\right)-g_{i}^{L}\left(a_{t}\right)\right)}$

Otherwise

Similarly, concordance relations can be renewed as follows if $i$-th criterion is cost criterion:

$$
\begin{array}{ll}
C_{i}\left(a_{t}, a_{s}\right)=1 & \text { if } \alpha_{i t} g_{i}^{L}\left(a_{t}\right) \\
C_{i}\left(a_{t}, a_{s}\right)=0 & \text { if } g_{i}^{L}\left(a_{t}\right) \geq \\
C_{i}\left(a_{t}, a_{s}\right)=\frac{g_{i}^{U}\left(a_{s}\right)-g_{i}^{L}\left(a_{t}\right)}{\left(1-\alpha_{i t}\right)\left(g_{i}^{U}\left(a_{t}\right)-g_{i}^{L}\left(a_{t}\right)\right)} & \text { Otherwise }
\end{array}
$$


Based on the above formulation and notation we can use the concept of concordance in Electre III for comparing and ranking interval numbers. In classical MADM methods, the performance values for criteria are known precisely, whereas in many types of real world decision making problems it is an unrealistic assumption that the knowledge and representation of a decision maker or expert are so precise. Often a decision-maker can evaluate the performance of various alternatives in relation to considered attributes by interval numbers. In such situation the comparison of two actions leads to the comparison of two interval numbers. By the above formulations we can use Electre III for decision making problems with interval numbers. In this case the veto thresholds $v_{i}\left(g_{i}(a)\right)$ can be considered very large numbers and the optimism level of the decision maker $\left(\alpha_{i j}\right)$ is determined by decision maker.

\section{Numerical Examples}

In order to demonstrate the applications of the above-mentioned approach, two numerical examples have been solved in this section. In example 1 a crisp decision matrix is represented and by using preference and indifference thresholds is converted to an interval decision matrix. Then the original decision matrix and also interval decision matrix are used respectively for ranking the alternatives. It is axiomatic that the results of two approaches are the same. In example 2 an interval decision matrix is represented and then the alternatives are ranked based on the optimism level of the decision maker.

\subsection{Example 1}

Consider the decision matrix, preference and indifference thresholds which have been shown in table 1. In this example preference and indifference thresholds has been defined for each criterion and the level of the decision maker $\left(\alpha_{i j}\right)$ is calculated based on these thresholds. Suppose that criteria C1, C2 and C3 are benefit criteria, which means the higher the score of a given criterion is, the more desirable it is. The criterion C4 is cost criterion, which means the lower the score of this criterion is, the more desirable it is.

Table 1

Decision matrix

\begin{tabular}{cccccc}
\hline & $\boldsymbol{C}_{\mathbf{1}}$ & $\boldsymbol{C}_{\mathbf{2}}$ & $\boldsymbol{C}_{\mathbf{3}}$ & $\boldsymbol{C}_{\mathbf{4}}$ \\
\hline & $\boldsymbol{A}_{\mathbf{1}}$ & 33 & 29 & 56 & 23 \\
& $\boldsymbol{A}_{\mathbf{2}}$ & 27 & 44 & 65 & 45 \\
& $\boldsymbol{A}_{\mathbf{3}}$ & 87 & 11 & 13 & 15 \\
& $\boldsymbol{A}_{\mathbf{4}}$ & 43 & 21 & 19 & 65 \\
& $\boldsymbol{A}_{\mathbf{5}}$ & 51 & 21 & 46 & 19 \\
& $\boldsymbol{A}_{\mathbf{6}}$ & 76 & 112 & 98 & 56 \\
\hline $\mathrm{q}$ & & 3 & 4 & 1 & 3 \\
$\mathrm{p}$ & & 6 & 9 & 7 & 9 \\
\hline & $\boldsymbol{\alpha}$ & 0.5 & 0.444 & 0.143 & 0.333 \\
\hline
\end{tabular}

It is possible to rewrite this decision matrix so that the elements of matrix become an interval numbers. This interval decision matrix has been shown in table 2. So it is possible to rank all alternatives based on the ELECTRE III method and also based on the presented approach in this paper. In this example the weights $w_{i}$ for all criteria are equal.Calculating the concordance matrix according to presented approach in this paper; we obtain the results pointed out in Table 3 . The concordance matrix based on the presented approach is as same as the one that generate based on the ELECTRE III method. Please note that no veto threshold is specified in this example. According to these results, the final ranking is: $A_{6}>A_{5}>A_{1} \sim A_{2}>A_{3}>A_{4}$. 
Table 2

Interval decision matrix

\begin{tabular}{ccccccccc}
\hline & \multicolumn{2}{c}{$\boldsymbol{C}_{\mathbf{1}}$} & \multicolumn{2}{c}{$\boldsymbol{C}_{\mathbf{2}}$} & \multicolumn{2}{c}{$\boldsymbol{C}_{\mathbf{3}}$} & \multicolumn{2}{c}{$\boldsymbol{C}_{\mathbf{4}}$} \\
\hline & $\mathrm{L} 1$ & $\mathrm{R} 1$ & $\mathrm{~L} 2$ & $\mathrm{R} 2$ & $\mathrm{~L} 3$ & $\mathrm{R} 3$ & $\mathrm{~L} 4$ & $\mathrm{R} 4$ \\
\hline $\boldsymbol{A}_{\mathbf{1}}$ & 33 & 39 & 29 & 38 & 56 & 63 & 14 & 23 \\
$\boldsymbol{A}_{\mathbf{2}}$ & 27 & 33 & 44 & 53 & 65 & 72 & 36 & 45 \\
$\boldsymbol{A}_{\mathbf{3}}$ & 87 & 93 & 11 & 20 & 13 & 20 & 6 & 15 \\
$\boldsymbol{A}_{\mathbf{4}}$ & 43 & 49 & 21 & 30 & 19 & 26 & 56 & 65 \\
$\boldsymbol{A}_{\mathbf{5}}$ & 51 & 57 & 21 & 30 & 46 & 53 & 10 & 19 \\
$\boldsymbol{A}_{\mathbf{6}}$ & 76 & 82 & 112 & 121 & 98 & 105 & 47 & 56 \\
\hline
\end{tabular}

Table 3

Concordance matrix

\begin{tabular}{ccccccc}
\hline Concordance & $\boldsymbol{A}_{\mathbf{1}}$ & $\boldsymbol{A}_{\mathbf{2}}$ & $\boldsymbol{A}_{\mathbf{3}}$ & $\boldsymbol{A}_{\mathbf{4}}$ & $\boldsymbol{A}_{\mathbf{5}}$ & $\boldsymbol{A}_{\mathbf{6}}$ \\
\hline $\boldsymbol{A}_{\mathbf{1}}$ & 1 & 0.5 & 0.5425 & 0.75 & 0.7075 & 0.25 \\
$\boldsymbol{A}_{\mathbf{2}}$ & 0.5 & 1 & 0.5 & 0.75 & 0.5 & 0.25 \\
$\boldsymbol{A}_{\mathbf{3}}$ & 0.5 & 0.5 & 1 & 0.5425 & 0.5 & 0.5 \\
$\boldsymbol{A}_{\mathbf{4}}$ & 0.3125 & 0.25 & 0.5 & 1 & 0.25 & 0 \\
$\boldsymbol{A}_{\mathbf{5}}$ & 0.5625 & 0.5 & 0.7075 & 1 & 1 & 0.25 \\
$\boldsymbol{A}_{\mathbf{6}}$ & 0.75 & 0.75 & 0.5 & 1 & 0.75 & 1 \\
\hline
\end{tabular}

As mentioned above, the results of presented approach and ELECTRE III is same. So it is possible to use this approach for decision making problems with interval numbers. In these problems we only need the optimism level of the decision maker $\left(\alpha_{i j}\right)$. This optimism level can be same or different for each criterion. In the next example a decision making problem with interval numbers is solved on the basis of offered approach.

\subsection{Example 2}

Consider the interval decision matrix that is shown in table 4. In this example three criteria are benefit criteria and $\alpha=0.3$ for all of them. The weights of criteria are $\left(w_{1}, w_{2}, w_{3}\right)=(0.3,0.5,0.2)$.

Table 4

Interval decision matrix

\begin{tabular}{cccc}
\hline Decision Matrix & $\mathbf{C}_{\mathbf{1}}$ & $\mathbf{C}_{\mathbf{2}}$ & $\mathbf{C}_{\mathbf{3}}$ \\
\hline $\mathrm{A}_{1}$ & {$[1,4]$} & {$[3,4]$} & {$[8,9]$} \\
$\mathrm{A}_{2}$ & {$[3,4]$} & {$[6,9]$} & {$[3,7]$} \\
$\mathrm{A}_{3}$ & {$[7,8]$} & {$[5,10]$} & {$[2,7]$} \\
$\mathrm{A}_{4}$ & {$[1,7]$} & {$[1,3]$} & {$[4,8]$} \\
\hline
\end{tabular}

Table 5 present concordance indexes which calculated on the basis of offered approach. According to this matrix the final ranking of alternatives is:

Table 5

Concordance matrix

\begin{tabular}{cllll}
\hline Concordance & $\boldsymbol{A}_{\mathbf{1}}$ & $\boldsymbol{A}_{\mathbf{2}}$ & $\boldsymbol{A}_{\mathbf{3}}$ & $\boldsymbol{A}_{\mathbf{4}}$ \\
\hline$A_{1}$ & 1 & 0.344 & 0.2 & 1 \\
$A_{2}$ & 0.8 & 1 & 0.7 & 1 \\
$A_{3}$ & 0.8 & 1 & 1 & 0.972 \\
$A_{4}$ & 0.3 & 0.485 & 0.2 & 1 \\
\hline
\end{tabular}




\section{Conclusion}

In this paper, the link between interval numbers and concordance matrix has been illustrated and based on this link, the concordance formulation alters so that ELECTRE III become usable in decision making problems with interval numbers. The proposed method not only does not change the concept of concordance relation and does not limit its application, but also makes ELECTRE III usable for decision making problems with interval numbers.

\section{References}

Cavallaro, F. (2010). A comparative assessment of thin-film photovoltaic production processes using the ELECTRE III method, Energy Policy, 38(2010) 463-474.

Giannoulis, C., \& Ishizaka, A. (2010). A Web-based decision support system with ELECTRE III for a personalized ranking of British universities. Decision Support Systems, 48, 488-497.

Mousseau, V., Bias, L.C. (2004). Valued outranking relations in ELECTRE providing manageable disaggregation procedures. European Journal of Operational Research, 156(2), 467-482.

Papadopoulos, A., \& Karagiannidis, A. (2008). Application of the multi-criteria analysis method Electre III for the optimization of decentralized energy systems. Omega, 36, 766- 776.

Rogers, M., \& Bruen, M. (2000). Using ELECTRE III to choose route for Dublin port motorway. Journal of Transportation Engineering. 126(4), 313-323.

Roy, B. (1978). ELECTRE III: Algorithme de classement base sur une representation floue des preferences en presence de criteres multiples. Cahiers de CERO, 20(11), 3-24.

Roy, B. (1996). Multicriteria Methodology for Decision Aiding. Kluwer Academic Publishers, Dordrecht.

Roy, B. (1991). The outranking approach and the foundations of ELECTRE methods. Theory and Decision, 31, 49-73.

Roy, B. (1968). Classement et choix en pr'esence de points de vue multiples (la m'ethode ELECTRE). Revue Franc, aise d'Informatique et de Recherche Op'erationnelle, 8, 57-75.

Sayadi, M.K., Heydari, M., \& Shahanaghi, K. (2009). Extension of VIKOR method for decision making problem with interval numbers. Applied Mathematical Modelling, 33, 2257-2262.

Catalina, T., Virgone, J., \& Blanco, E. (2011). Multi-source energy systems analysis using a multicriteria decision aid methodology. Renewable Energy, 36, 2245-2252. 